\title{
Evaluation of autonomic nervous system functions in frame of heart rate variability in children with inflammatory bowel disease in remission
}

\author{
Helen Aghdasi-Bornaun ${ }^{1}$, Günsel Kutluk², Gonca Keskindemirci ${ }^{3}$, Kazım Öztarhan ${ }^{1}$, \\ Reyhan Dedeoğlư ${ }^{4}$ Nuh Y1lmaz ${ }^{5}$, Öykü Tosun ${ }^{6}$ \\ Departments of ${ }^{1}$ Pediatric Cardiology, ${ }^{2}$ Pediatric Gastroenterology Hepatology and Nutrition and ${ }^{3}$ Pediatrics, University \\ of Health Sciences Kanuni Sultan Süleyman Education and Research Hospital; ${ }^{4}$ Department of Pediatric Cardiology, \\ Istanbul University Cerrahpaşa Medical Faculty; ${ }^{5}$ Department of Pediatric Cardiology, İstinye University Medical Faculty, \\ ${ }^{7}$ Department of Pediatric Cardiology, Medeniyet University Medical Faculty, Istanbul, Turkey. \\ E-mail: helen_borna@yahoo.com.tr
}

Received: 4th August 2017, Revised: 1st October 2017, Accepted: 27th November 2017

SUMMARY: Aghdasi-Bornaun H, Kutluk G, Keskindemirci G, Öztarhan K, Dedeoğlu R, Yılmaz N, Tosun Ö. Evaluation of autonomic nervous system functions in frame of heart rate variability in children with inflammatory bowel disease in remission. Turk J Pediatr 2018; 60: 407-414.

Heart Rate Variability (HRV) is one of the reliable and noninvasive parameters to evaluate autonomic control of the cardiovascular system in patients. The aim of our study was to assess autonomic function in pediatric patients with inflammatory bowel disease (IBD) in remission using Power Spectral Analysis of HRV. Autonomic cardiovascular function was evaluated by time and frequency-domain indexes of spontaneous heart rate in 36 IBD children patients in remission phase and 36 sex and age matched healthy controls. Twenty children with Ulcerative Colitis (UC) and 16 patients with Crohn's disease (CD) were diagnosed according to their history, physical and laboratory examination, endoscopic, histopathological and radiological findings of upper and lower gastrointestinal system. Significant decrease was observed at HRV parameters in IBD patients when compared with control group. These differences was found in some of time domain parameters (NNmean, SDNNtotal, SDNNday) and frequency domain parameters (TP, LF,VLF) $(p<0.05)$. Also, there was a significant higher minimum heart rate ratio $(\mathrm{p}<0.04)$ in patients in comparison to the control group. In the IBD group, there was a relative tendency for parasympathetic suppression and sympathetic predominance which reflects an autonomic dysfunction. This imbalance has a circadian rhythm and it is more obvious during the day. These observations may suggest a previously unrecognized role of chronic inflammation for autonomic modulation in IBD.

Key words: inflammatory bowel disease, heart rate variability, pediatrics.

Inflammatory Bowel Disease (IBD) is a multifactorial disease which represents a group of intestinal disorders that causes prolonged inflammation of the digestive tract and is frequently associated with extraintestinal manifestations of illness. ${ }^{1}$

Three types of IBD, Crohn's disease (CD), ulcerative colitis (UC) and indeterminate colitis
(IC) tend to occur in early adulthood, but may be seen at any age from early childhood to advanced ages. While UC comprises mostly (except backwash ileitis) only the colon, whole gastrointestinal system (GIS) from mouth to the anus can be affected in CD. Genetic susceptibility, immun disregulation and varied response to gut microorganisms and unknown

This paper was presented at the $14^{\text {th }}$ National Pediatric Cardiology and Heart Surgery Congress, 15-18 April 2015, Denizli, Turkey (Poster Number: 368) 
triggering events may lead to process of the disease. ${ }^{1,2}$

The autonomic nervous system (ANS) specifically the parasympathetic system has been proposed to mediate communication between the brain-gut axis and modulate gastrointestinal autoregulation. ${ }^{3}$ It is widely recognized that autonomic dysfunction (AD) may play a key role in the pathophysiology of the inflammatory response in the gastrointestinal system, associated with systemic manifestations and altered gut motility and immune response that may contributed to functional symptoms of IBD. 3,4

One of the best methods that evaluates the sympathetic-parasympathetic balance in the ANS is the Heart Rate Variability (HRV) measurements. ${ }^{2-4}$ In this study, we aimed to evaluate the variabilities of ANS in IBD patients in comparison with a control group by using HRV analyzes. We also tried to determine the cardiac involvement as a systemic manifestation in the process of the disease and evaluate the effects of disease on ANS and its correlation with changes in cardiac vagal activity in IBD pateints.

\section{Material and Methods}

A total of 36 pediatric patients with IBD, (20 with UC and 16 patients with CD) were enrolled prospectively in this study. The patients were followed-up in our pediatric outpatient gastroenterology clinic for at least 12 months and they were all in remission. The diagnosis of UC or CD was made according to their history, physical and laboratory examination, endoscopic, histopathological and radiological findings of the upper and lower gastrointestinal system. All subjects were in the remission phase of illness according to Pediatric Ulcerative Colitis Activity Index (PUCAI) ${ }^{5}$ or Pediatric Crohn's Disease Activity Index (PCDAI) ${ }^{6}$ scores and no relapses of IBD were seen during the past 3 months before the holter ECG recording test. Thirty-six age and sex matched healthy controls were enrolled in the study. IBD patients were using mesalamin and azathiopurin and free of steroids. Patients did not receive any medication for one day before the test. None of the participants in the control group were using any medications. Pateints with existing cardiac conditions, those using arryhthmogenic medication, having systemic disease, acute or chronic infection, anemia, electrolyte imbalances and the other diseases known to affect the ANS were excluded from the study.

The local ethical committee of our hospital approved the study and informed consents of parents and subjects were obtained.

Both groups were evaluated by the same cardiologist. A protocol consisted of a detailed history, physical examination, 12lead electrocardiogram (ECG), transthoracic echocardiography and 24-hour Holter recordings were performed.

Echocardiographic analysis: Standard transthoracic echocardiogram (TTE) were obtained by using General Electric (GE) S7 Pro, Florida, USA) equipped with a $3 \mathrm{MHz}$ transducer to evaluate cardiac function. TTE involved M-mode, two-dimensional Doppler flow assessments, and tissue Doppler indices (TDI) measurements. Left ventricular Ejection fraction (EF) was calculated by modified Simpson's method ${ }^{7}$.

Electrocardiography analysis: QTc intervals were measured using Bazett's Formula ${ }^{8}$ in two groups.

Heart rate variability analysis: A standard ambulatory ECG recording system (Century 2000/3000 HRV Package System, version 1.32, Biomedical Systems, St. Louis, ABD) was used. They were manually calculated for R-R intervals and analyzed by using this package system. In this analysis, only the cycles with normal morphologic characterized beats were used, artifacts and ectopic complexes were excluded. In each person holter recordings lasted at least 23 hours. The HRV was evaluated by analysis time domain and frequency domain parameters (Table I)..$^{2-4}$ Analysis of time and frequency domain parameters were performed in 3 stages: The current study was initiated by assessing differences over the whole 24 hour period, then we examined differences during the daytime (07:00 to 22:00) and at night (22:00 to 07:00). Spectral measurements were calculated by Fast Fourier converting method. ${ }^{9,10}$

\section{Statistical Analysis}

All data were processed by using NCSS (Number Cruncher Statistical System) 2007 Statistical Software (Utah, USA) for statistical 
Table I. Definition of Time and Frequency Domain HRV Parameters Obtained From 24-Hour Holter Recordings.

\begin{tabular}{|c|c|c|c|c|c|}
\hline Time & Domain & Analysis & Frequency & Domain & analysis \\
\hline Parameters & Description & Relevance & Parameters & Description & Relevance \\
\hline $\begin{array}{l}\text { SDNN } \\
\text { (day and } \\
\text { night) } \\
\text { (ms) }\end{array}$ & $\begin{array}{l}\text { Standard deviation of } \\
\text { the all NN interval. } \\
\text { Reflects all the } \\
\text { cyclic components } \\
\text { responsible for } \\
\text { variability in the } \\
\text { period of the } \\
\text { recording. }\end{array}$ & $\begin{array}{l}\text { Reflects both } \\
\text { sympathetic and } \\
\text { parasympathetic activity. } \\
\text { A decrease in SDNN } \\
\text { has been associated } \\
\text { with SCD* }\end{array}$ & $\begin{array}{l}\text { Total Power } \\
\text { (TP) Hz } \\
\text { (ms2) }\end{array}$ & $\begin{array}{l}\text { Frequency range } \\
\text { between } 0-0.4 \mathrm{~Hz} \\
\mathrm{TP}=\mathrm{VLF}+\mathrm{LF}+\mathrm{HF}\end{array}$ & $\begin{array}{l}\text { Reflects a estimate } \\
\text { of the total power } \\
\text { of the spectral } \\
\text { density (the overall } \\
\text { activity of the } \\
\text { ANS*) }\end{array}$ \\
\hline $\begin{array}{l}\operatorname{meanNN} \\
(\mathrm{ms})\end{array}$ & $\begin{array}{l}\text { Mean normal-to- } \\
\text { normal }(\mathrm{NN}) \text { intervals } \\
\text { during the entire } \\
\text { recording }\end{array}$ & $\begin{array}{l}\text { Reflects parasympathetic } \\
\text { activity }\end{array}$ & $\begin{array}{l}\text { High } \\
\text { Frequency } \\
\text { power (HF) }\end{array}$ & $\begin{array}{l}\text { Frequency range } \\
\text { between } 0.15 \text { and } 0.4 \\
\mathrm{~Hz} \text { ) }\end{array}$ & $\begin{array}{l}\text { Reflects the } \\
\text { parasympathetic } \\
\text { activity }\end{array}$ \\
\hline $\begin{array}{l}\text { pNN50 } \\
(\%)(\mathrm{ms})\end{array}$ & $\begin{array}{l}\text { The proportion of } \\
\text { adjacent NN intervals } \\
\text { that differ by> } 50 \mathrm{~ms} \\
\text { in the } 24 \text { hours }\end{array}$ & $\begin{array}{l}\text { Reflects parasympathetic } \\
\text { activity }\end{array}$ & $\begin{array}{l}\text { Low } \\
\text { Frequency } \\
\text { power(LF) }\end{array}$ & $\begin{array}{l}\text { Frequency range } \\
\text { between } 0.04 \text { and } \\
0.15 \mathrm{~Hz}\end{array}$ & $\begin{array}{l}\text { Reflect mixed } \\
\text { sympathetic and } \\
\text { parasympathetic } \\
\text { activities }\end{array}$ \\
\hline $\begin{array}{l}\text { SDANN } \\
\text { index } \\
(\mathrm{ms})\end{array}$ & $\begin{array}{l}\text { The standard deviation } \\
\text { of the mean } \mathrm{N}-\mathrm{N} \\
\text { intervals of } 5 \text {-minutes } \\
\text { segments }\end{array}$ & $\begin{array}{l}\text { Reflects circadian } \\
\text { influences of autonomic } \\
\text { function. }\end{array}$ & $\begin{array}{l}\text { Very Low } \\
\text { Frequency } \\
\text { power (VLF) }\end{array}$ & $\begin{array}{l}\text { Frequency range } \\
\text { between } 0.0033 \text { and } \\
0.04 \mathrm{~Hz}\end{array}$ & $\begin{array}{l}\text { Reflect the overall } \\
\text { activity of slow } \\
\text { mechanisms } \\
\text { of sympathetic } \\
\text { function }\end{array}$ \\
\hline $\begin{array}{l}\text { RMSSD } \\
(\mathrm{ms})\end{array}$ & $\begin{array}{l}\text { The square root of } \\
\text { the mean squared } \\
\text { differences of } \\
\text { successive NN interval }\end{array}$ & $\begin{array}{l}\text { Reflects parasympathetic } \\
\text { activity }\end{array}$ & $\begin{array}{l}\text { Ultra-Low } \\
\text { Frequency } \\
\text { power } \\
\text { (ULF) }\end{array}$ & $\begin{array}{l}\text { Frequency range the } \\
\text { area }<0.0033 \mathrm{~Hz}\end{array}$ & $\begin{array}{l}\text { Reflect mixed the } \\
\text { sympathetic and } \\
\text { the parasympathetic } \\
\text { activity }\end{array}$ \\
\hline $\begin{array}{l}\text { SDNN } \\
\text { index } \\
(\mathrm{ms})\end{array}$ & $\begin{array}{l}\text { Mean of the standard } \\
\text { deviations of all } \\
\text { normal sinus } \mathrm{NN} \\
\text { intervals for all } 5 \text {-min } \\
\text { segments }\end{array}$ & $\begin{array}{l}\text { Reflects both } \\
\text { sympathetic and } \\
\text { parasympathetic activity } \\
\text { (measure primarily of } \\
\text { autonomic influence on } \\
\text { HRV) }\end{array}$ & $\begin{array}{l}\text { Low } \\
\text { Frequency } \\
\text {-to-High } \\
\text { Frequency } \\
\text { power ratio } \\
\text { (LF/HF) }\end{array}$ & $\begin{array}{l}\text { High values of the } \\
\text { LF/HF ratio indicate } \\
\text { a dominance of } \\
\text { sympathetic activity, } \\
\text { while low values } \\
\text { indicate a dominance } \\
\text { of parasympathetic } \\
\text { activity }\end{array}$ & $\begin{array}{l}\text { Reflects the } \\
\text { sympathetic and } \\
\text { parasympathetic } \\
\text { balance }\end{array}$ \\
\hline
\end{tabular}

meanNN: mean interval between two heartbeats, pNN50: the percentage of successive intervals that differ by more than 50 ms, RMSSD: Root mean square of successive RR interval differences, SDANN: Standard deviation of the average NN intervals for each $5 \mathrm{~min}$ segment of a $24 \mathrm{~h}$ HRV Recording, SDNN: Standard deviation of NN intervals ANS*: Autonomic Nervous System

SCD*: Sudden Cardiac Death

analyses. In evaluating the data, we used descriptive statics (mean value and \pm standard deviaton) and also we used unpaired test to evaluate couple groups and qualitative data were compared with Chi square test. $\mathrm{P}<0.05$ was considered to be significant.

\section{Results}

Sixteen children with CD, 20 children with UC patients; totally 36 sex and age matched controls were enrolled to the study. The mean age was $11.96 \pm 4.47$ in patients and $12.01 \pm 4.2$ in controls, with $52.7 \%(\mathrm{n}=19)$ female and $47.3 \%(n=17)$ male individuals.

The clinical, electrocardiographic and echocardiographic parameters of the patient and control group are displayed in Table II. There were no significant differences in presenting features between the two groups.

The patients were all in remisssion phase (PUCAI score $=1 \mathrm{LF} 1.85 \pm 5.16$ and PCDAI score $=4.25 \pm 2.3$ ), Mean disease duration of the patients was $16.7 \pm 3.43$ months. Also, there were no statistically significant differences regarding to age, gender, body mass index among partients with CD, UC and healthy controls (Table III).

The statistically significant differences were found in time domain indexes, between study and control group in values of Standard deviation of the all NN (normal-to-normal) interval (SDNN)total, The standard deviation 
Table II. The Demographic Characteristics, Echocardiographic and QTc Features of the Patient and Control Groups.

\begin{tabular}{llll}
\hline & $\begin{array}{l}\text { Patients } \\
\text { CD }(16)+\mathrm{UC}(20)\end{array}$ & $\begin{array}{l}\text { Control } \\
(36)\end{array}$ & $\mathrm{p}$ \\
\hline Age (years) & $12.10 \pm 4.48$ & $12.11 \pm 4.49$ & $\mathrm{NS}$ \\
BMI $(\mathrm{kg} / \mathrm{m})$ & $19.58 \pm 3.98$ & $18.99 \pm 3.89$ & $\mathrm{NS}$ \\
Sex $(\mathrm{male} / \mathrm{female})$ & $17(47.22 \%) / 19(52.78 \%)$ & $17(47.22 \%) / 19(52.78 \%)$ & $\mathrm{NS}$ \\
SBP $(\mathrm{mmHg})$ & $101.81 \pm 10.37$ & $98.41 \pm 12.57$ & $\mathrm{NS}$ \\
DBP (mmHg) & $55.06 \pm 10.16$ & $56.92 \pm 9.91$ & $\mathrm{~N}$ \\
LVEDD & $43.47 \pm 6.91$ & $41.54 \pm 6.65$ & $\mathrm{NS}$ \\
LVESD & $27.06 \pm 4.74$ & $27.4 \pm 3.07$ & $\mathrm{NS}$ \\
EF & $69.75 \pm 5.72$ & $70.64 \pm 6.16$ & $\mathrm{NS}$ \\
FC & $34.89 \pm 8.11$ & $35.21 \pm 8.15$ & $\mathrm{NS}$ \\
Doppler mitral E/A & $1.74 \pm 0.32$ & $1.80 \pm 0.16$ & $\mathrm{NS}$ \\
Tissue mitral E/A & $2.37 \pm 0.46$ & $2.49 \pm 0.35$ & $\mathrm{NS}$ \\
QTc & $387.97 \pm 15.57$ & $391.75 \pm 13.94$ & $\mathrm{NS}$ \\
\hline
\end{tabular}

BMI: body mass index; BSA: body surface area; DBP: diastolic blood pressure; LVEDD: left ventricular end-diastolic diameter; LVEF: left ventricular ejection fraction; FC: foesed shortening; LVESD: left ventricular end-systolic diameter; SBP: systolic blood pressure; E/A: the ratio of early to late peak velocities(doppler and tissue); QTc;The Corrected QT Interval

of the mean N-N intervals (SDANN)index, SDNN day and $(\mathrm{NN})$ mean parameters $(\mathrm{p}=0.34$, $0.025,0.031,0.029$, respectively). Although the mean results of the other parameters of time domain indexes (The square root of the mean squared differences of successive NN interval (RMSSD), SDNN index, and The proportion of adjacent NN intervals that differ by $>50 \mathrm{~ms}$ in the 24 hours (pNN) 50 were also lower in IBD patients compared with the control group, these differences were not statistically significant ( $p>0.05)$. In addition, the minimum HR was significantly higher in patient group in comparision with the control group $(p=0.28)$. At frequency-domain indexes analysis; mean values of total power (TP), low frequency (LF) and very low frequency (VLF) parameters were significantly lower in patient group compared with the control group $(p=0.023,0.022,0.023$, respectively). Although patients also had lower high frequency (HF) activity and LF/HF ratio in comparison to controls; these differences were not statistically significant ( $\mathrm{p}>0.05$ ) (Table IV).

The UC and CD groups were compared according to Echocardiographic, ECG and Holter ECG monitoring results, the differences between the groups were not statistically significant $(p>0.05)$ (Table V).

\section{Discussion}

IBDs is an example of pathological entities having multifactorial etiology. Although there have been a lot of studies investigating the pathogenesis of IBD, it is still not fully understood. The most widely accepted idea that diseases emerge as a result of the alterations in immune response of the intestinal mucosa in both UC and CD patients. ${ }^{11}$ There is an increasing amount of evidence that autonomic dysfunction may play a role in the pathophysiology of the inflammatory response in the gastrointestinal system. ${ }^{12,13}$ Several investigators have reported that ANS, especially the parasympathetic system modulates the immune response in chronic inflammatory disorders. ${ }^{2,3,12}$

Autonomic nervous system activity can be assesed with HRV which is a non-invasive technique in both healthy individuals and in patients with cardiovascular disorder. ${ }^{14,15} \mathrm{HRV}$ reflects the balance of sympathetic and vagal activity on the sinus node. Parasympathetic stimulation slows the heart rate, whereas the heart rate is accelerated by sympathetic stimuli. ${ }^{16}$ A high HRV is an indicator of healthy autonomic and cardiovascular response. Lower HRV is associated with a greater possibility of cardiovascular events 
Table III. Clinical Features of the UC and CD Groups.

\begin{tabular}{|c|c|c|}
\hline & $\mathrm{CD}(\mathrm{n}: 16)$ & UC (n:20) \\
\hline Age, years & $12.8 \pm 3.97$ & $11.55 \pm 4.8$ \\
\hline Gender, males/females & $9 / 7$ & $8 / 12$ \\
\hline Disease duration (months) & $16.5 \pm 3.3$ & $16.8 \pm 3.6$ \\
\hline Extent of the disease & $\begin{array}{l}\mathrm{L}^{*} \mathrm{n}=9 \\
\mathrm{~L}^{* *} \mathrm{n}=6 \\
\mathrm{~L} 3 \mathrm{~B}^{* * *} \quad \mathrm{n}=1\end{array}$ & $\begin{array}{ll}\text { E2 }^{\#} & n=2 \\
\text { E3 }^{\# \#} & n=2 \\
\text { E4 }^{\# \# \#} & n=16\end{array}$ \\
\hline PCDAI score & $4.25 \pm 2.3$ & $\mathrm{~N} / \mathrm{A}$ \\
\hline PUCAI score & $\mathrm{N} / \mathrm{A}$ & $11.85 \pm 5.16$ \\
\hline
\end{tabular}

PUCAI; Pediatric Ulcerative Colitis Activity Index, PCDAI; Pediatric Crohn's Disease Activity Index, IBD; Inflammatory Bowel Disease. L1*: Terminal ileum, L2**: Colon, L3B3p ${ }^{* * *}$ :Ileocolon perianally penetrating, E2 $2^{\#}$ : Rectosigmoid+descending colon, E3"\#: Rectosigmoid+descending+transvers colon E4"\#\#: Pancolitis

and it indicates inadequate adaptation of the ANS. ${ }^{14,15}$ Sympathetic predominance could have prognostic value in morbidity/mortality of different diseases, while increased vagal activity is protective against dysrhythmias. ${ }^{14,15}$ The parameter of TP has been shown to be the most significant prognostic value among HRV parameters. The TP as well as HF are the indicators of parasympathetic activity but physiological correlation in the parameters of Ultra low frequency ULF and VLF are still unknown.

Studies on the interaction between IBD and ANS had started in 1928 by Bokus. ${ }^{17}$ In this study, he suggested that the imbalance of the ANS was responsible for IBD. In a recent study of Jelenova et al., ${ }^{18}$ which is the only study conducted in pediatric population with IBD, HRV methods were used in detection of autonomic instabilities in 29 children with IBD (19 of CD and 10 of UC). Most of these children were evaluated during the remisson phase. They observed reduced HRV parameters, especially lower LF, VLF levels and LF/HF ratios in the patient group. They reported a deterioration in parasympathetic cardiac modulation in IBD pateints.

In our current study, we compared the cardiovascular autonomic control both in pediatric patients with IBD in remisson and healthy controls by using spectral analysis of HRV. There were no statistically significant difference between the two groups regarding the results of average age, gender and body surface area (BSA) between the two groups ( $>$ 0.05). This helps to eliminate the effects of age and gender on the normal range of HRV. ${ }^{19}$ Our results showed a decrease in all time domain parameters of HRV in the study group. From these parameters, indices of vagal activity including SDNN, SDNNday, SDANNindex and meanNN values were statistically significant. Also, patient groups tended to display lower values of frequency domain parametes, but only the differences in values of TP, LF and VLF were found to be statistically significant. Our findings support the results of Jelenova et al. ${ }^{18}$ that showed a significant suppression in some of the components of HRV system, especially the parasympathetic system. It reflects a reduced parasympathetic nervous system activity, while sympathetic nervous system seems to be more active in children with IBD compared with the control group. In addition, an increase in the minimum 24 hour heart rate in the patient group may indicate a disruption of the ANS in IBD patients. Furthermore, the analysis of circadian rhythm results in our study revealed that the differences in SDNN values during the daytime hours were significant.

The previous studies about HRV showed a significantly increased sympathetic tone during the day especially in the beginning of waking, while there was dominance of vagal tone during the night. ${ }^{4,20}$ Our results confirmed that this imbalance may have a circadian rhythm and it was consistent with the results of previous studies.

In past reports, it was indicated that concomitant therapies with corticosteroids, mesalamine or azathioprine did not cause autonomic abnormalities in IBD patients. ${ }^{11,12,21}$ Even though, low potential risk of arrhythmogenic effect is expected for these drugs, it needs to 
Table IV. Comparison of All HRV Indexes Between IBD Patients and Control Groups.

\begin{tabular}{llll}
\hline & Study group n:36 & Control group n:36 & $\mathrm{p}$ \\
\hline HR (average) & $91.44 \pm 12.89$ & $86.58 \pm 11.38$ & $\mathrm{NS}$ \\
HR (min) & $50.74 \pm 6.82$ & $47.39 \pm 5.7$ & .028 \\
HR (max) & $166.19 \pm 18.34$ & $161.00 \pm 12.91$ & $\mathrm{NS}$ \\
SDNNT & $133.03 \pm 43.79$ & $155.39 \pm 43.89$ &, 034 \\
SDANN Index & $122.47 \pm 46.51$ & $146.03 \pm 40.37$ &, 025 \\
SDNN Index & $60.00 \pm 17.46$ & $67.61 \pm 19.23$ & $\mathrm{NS}$ \\
RMSSD TOTAL & $41.75 \pm 16.99$ & $45.72 \pm 16.55$ & $\mathrm{NS}$ \\
PNN50 TOTAL & $16.44 \pm 11.21$ & $20.58 \pm 11.35$ & $\mathrm{NS}$ \\
SDNN day & $112.64 \pm 43.98$ & $133.72 \pm 36.99$ & 0.031 \\
RMSSD day & $37.03 \pm 17.45$ & $39.53 \pm 13.01$ & $\mathrm{NS}$ \\
PNN50 day & $14.31 \pm 12.28$ & $15.75 \pm 8.72$ & $\mathrm{NS}$ \\
SDNN night & $108.94 \pm 37.15$ & $125.47 \pm 41.26$ & $\mathrm{NS}$ \\
RMSSD night & $50.64 \pm 21.69$ & $57.61 \pm 26.76$ & $\mathrm{NS}$ \\
PNN50 night & $25.75 \pm 16.01$ & $31.19 \pm 18.18$ & $\mathrm{NS}$ \\
NN MEAN & $671.70 \pm 100.77$ & $720.55 \pm 84.47$ & 0.029 \\
TP & $3685.90 \pm 1967.56$ & $4867.63 \pm 2342.77$ & 0.023 \\
ULF & $56.05 \pm 48.54$ & $56.29 \pm 38.61$ & $\mathrm{NS}$ \\
VLF & $2360.06 \pm 1340.42$ & $3215.60 \pm 1729.33$ & 0.022 \\
LF & $792.62 \pm 409.21$ & $1026.09 \pm 443.54$ & 0.023 \\
HF & $477.2306 \pm 280.98$ & $569.67 \pm 271.45$ & NS \\
LF/HF & $1.91 \pm 0.73$ & $2.04 \pm 0.85$ & $\mathrm{NS}$ \\
\hline
\end{tabular}

HF: high frequency; LF: low frequency; VLF:very low frequency; ULF:ultra low frequency; RMSDD: the square root of the sum of the square of the differences between successive R-R intervals; SDANN: the standard deviation of the mean N-N intervals of 5-minute segments; SDNN: the standard deviation of all N-N intervals; TP: total power; LF/HF: the ratio of LF to HF; PNN50: Percentage of NN Intervals Greater than $50 \mathrm{~ms}$; MeanNN: mean of all R-R intervals ; SDANN index:standard deviation of all the 5-minute NN interval; NS:non significant

be considered in patients who present with cardiac symptoms. Although this medical therapy is unlikely to affect our results, our patients did not take their medications for one day before testing. Steroid therapies are used for remission induction in the treatment of active IBD22 . Our patients were in clinical remission phase, therefore they were free of steroid therapy.

One further result of current study was comparing the HRV parameters between CD and UC patients that showed similar results in both groups. We know that UC and CD are two clinical presentations of inflamatory process, therefore such results were expected from this study.

In contrast with our results, there is a conflict about pathological findings suggesting mostly sympathetic involvement in some studies and obvious parasympathetic pathology in others. ${ }^{20,23-25}$ According to the results of the surveys, in some studies autonomic dysfunction was found only in UC, CD alone or in both independently of disease activity.2,6,20,21,23-25 We could not explain these diversities and differences in the results of these studies.

Altered HRV in healthy looking patients in remisson with no evidence of heart disease may suggest a subclinical inflammation or ANS abnormality concomitant with these systemic autonomic derangement free from disease activity.

The significant limitations of this study were the lack of normal reference values, complexity and the low patient number. Short-term HRV measurements are limited by a strict definition 
Table V. Comparison of All HRV Indexes Between the CD and UC Patients.

\begin{tabular}{llll}
\hline & CD n:16 & CU n:20 & $\mathrm{p}$ \\
\hline SDNNT & $137.27 \pm 52.7$ & $130.1 \pm 38.24$ & $\mathrm{NS}$ \\
SDANN Index & $125.2 \pm 58.77$ & $120.5 \pm 37.81$ & $\mathrm{NS}$ \\
SDNN Index & $61.4 \pm 17.39$ & $59.05 \pm 18.33$ & $\mathrm{NS}$ \\
RMSSD TOTAL & $42.13 \pm 17.67$ & $41.4 \pm 17.36$ & $\mathrm{NS}$ \\
PNN50 TOTAL & $18.13 \pm 12.85$ & $14.95 \pm 10.21$ & $\mathrm{NS}$ \\
SDNNDAY & $116.93 \pm 42.67$ & $109.9 \pm 46.84$ & $\mathrm{NS}$ \\
RMSSD day & $38.07 \pm 18.13$ & $36.3 \pm 17.81$ & $\mathrm{NS}$ \\
PNN50 day & $15.13 \pm 13.2$ & $13.7 \pm 12.19$ & $\mathrm{NS}$ \\
SDNN night & $105.2 \pm 35.1$ & $111.05 \pm 40.11$ & $\mathrm{NS}$ \\
RMSSD night & $49.67 \pm 20.69$ & $51.1 \pm 2343$ & $\mathrm{NS}$ \\
PNN50 night & $25.27 \pm 15.83$ & $25.55 \pm 16.75$ & $\mathrm{NS}$ \\
NN Mean & $677.18 \pm 109.21$ & $670.36 \pm 103.4$ & $\mathrm{NS}$ \\
TP & $3792.93 \pm 1918.5$ & $3618.48 \pm 2098.09$ & $\mathrm{NS}$ \\
ULF & $63.37 \pm 62.16$ & $52.4 \pm 36.96$ & $\mathrm{NS}$ \\
VLF & $2441.69 \pm 1293.29$ & $2314.61 \pm 1436.88$ & $\mathrm{NS}$ \\
LF & $834.98 \pm 439.94$ & $757.3 \pm 403.56$ & $\mathrm{NS}$ \\
HF & $452.91 \pm 222.02$ & $494.27 \pm 329.1$ & $\mathrm{NS}$ \\
LF/HF & $1.9 \pm 0.53$ & $1.92 \pm 0.86$ & $\mathrm{NS}$ \\
QTC & $386 \pm 16.51$ & $389.15 \pm 15.47$ & $\mathrm{NS}$ \\
EF & $70.4 \pm 7.4$ & $69.55 \pm 4.22$ & $\mathrm{NS}$ \\
DEA & $1.73 \pm 0.35$ & $1.71 \pm 0.28$ & $\mathrm{NS}$ \\
TEA & $2.33 \pm 0.49$ & $2.41 \pm 0.46$ & $\mathrm{NS}$ \\
\hline
\end{tabular}

HF: high frequency; LF: low frequency; VLF: very low frequency; ULF: ultra low frequency; RMSDD: the square root of the sum of the square of the differences between successive R-R intervals; SDANN: the standard deviation of the mean N-N intervals of 5-minute segments; SDNN: the standard deviation of all N-N intervals; TP: total power; LF/HF: the ratio of LF to HF; PNN50: Percentage of NN Intervals Greater than $50 \mathrm{~ms}$; MeanNN: mean of all R-R intervals; SDANN index:standard deviation of all the 5-minute NN interval; NS:Non significant

of abnormality. We used only one method (24-hour ambulatory ECG) to analyse the $\mathrm{AD}$, but no other ANS function markers were included in our study group. Interpretation of the current results are limited by the study's relatively small size, hence our sample may not be representative of the population of IBD patients. Thus, such research requires ongoing collaborations between many investigators and institutions.

In conclusion, we found that patients with IBD in clinical remission have significant reduction in some of the HRV parameters compared to the control group, which may reflect changes in the autonomic sympathovagal balance. In the future, enhanced cardiac morbidity and mortality may correlate with this $A D$ in the young IBD group. Furthermore, it will be important to determine whether reduced overall HRV is a result of the nature of IBD disease or whether the abnormalities in the autonomic regulation system precede and perhaps predispose subjects to the onset of IBD. To prove this theory, we need large-scale studies containing further research, different subgroups of IBD patients, additional analyzing methods and long term cardiac follow-up.

\section{REFERENCES}

1. Wehkamp J, Götz M, Herrlinger K, Steurer W, F Stange EF. Inflammatory bowel disease Crohn's disease and ulcerative colitis. Dtsch Arztebl Int 2016; 113: 72-82.

2. Sharma P, Makharia GK, Ahuja V, Dwivedi SN, Deepak KK. Autonomic dysfunctions in patients with inflammatory bowel disease in clinical remission. Digest Dis Sci 2009; 54: 853-861. 
3. Furlan R, Ardizzone S, Palazzolo L, et al. Sympathetic overactivity in active ulcerative colitis: effects of clonidine. Am J Physiol Regul Integr Comp Physiol 2006; 290: R224-R232.

4. Furlan R, Guzzetti S, Crivellaro W, et al. Continuous 24.hour assessment of the neural regulation of systemic arterial pressure and RR variabilities in ambulant subjects. Circulation 1990; 81: 537-547.

5. Turner D, Otley AR, Mack D, et al. Development, validation, and evaluation of a pediatric ulcerative colitis activity index: a prospective multicenter study. Gastroenterology 2007; 133: 423-432.

6. Hyams JS, Ferry GD, Mandel FS, et al. Development and validation of a pediatric Crohn's disease activity index. J Pediatr Gastroenterol Nutr 1991; 12: 439-447.

7. Wang M, Yip GW, Wang AY, Zhang Y. Peak Early Diastolic Mitral Annulus Velocity by Tissue Doppler Imaging Adds Independent and Incremental Prognostic Value. JACC 2003; 41: 5.

8. Bornaun HA, Yilmaz N, Kutluk G, et al. Prolonged P-wave and QT dispersion in children with inflammatory bowel disease in remission. Biomed Res Int 2017; 2017: 6960810 .

9. Dantas EM, Sant'Anna ML, Andreão RV, et al. Spectral analysis of heart rate variability with the autoregressive method: What model order to choose?. Comput Biol Med 2012; 42: 164-170.

10. Marek M. Committee of the Task Force. Heart rate variability: standards of measurement, physiological interpretation and clinical use. Task Force of the European Society of Cardiology and the North American Society of Pacing and Electrophysiology. Circulation 1996; 93: 1043-1065.

11. Kucharzik T, Maaser C, Lügering A, et al. Recent understanding of IBD pathogenesis: implications for future therapies. Inflamm Bowel Dis 2006; 12: f1068-f1083.

12. Furlan R, Ardizzone S, Palazzolo L, Rimoldi A. Sympathetic overactivity in active ulcerative colitis: effects of clonidine. Am J Physiol Regul Integr Comp Physiol 2006; 290: 224-232.

13. Bishop AE and Polak JM. The gut and the autonomic nervous system. In: Autonomic Failure: a Textbook of Clinical Disorders of the Autonomic Nervous System, edited by Bannister R and Mathias CJ. Oxford. 1992: 160-177.
14. Tsuji H, Larson M.G, Venditti FJ, et al. Impact of reduced heart rate variability on risk for cardiac events: the Framingham Heart Study. Circulation 1996; 94: 2850-2855.

15. Yadav RK, Gupta R, Deepak KK. A pilot study on short term heart rate variability \& its correlation with disease activity in Indian patients with rheumatoid arthritis. Indian J Med Res 2012; 136: 593-598.

16. Stein PK, Bosner MS, Kleiger RF, Conger BM. Heart rate variability: a measure of cardiac autonomic tone. Am Heart J 1994; 127: 1376-1381.

17. Bockus HI, Bank J, Wilkinson SA. Neurogenic mucous colitis. Am J Med Sci 1928; 176: 813-829.

18. Jelenova D, Ociskova M, Prasko J, Hunkova M. Heart rate variability in children with inflammatory bowel diseases. Neuro Endocrinol Lett 2015; 36: 72-79.

19. Taneja T, Mahnert BW, Passman R, et al. Effects of sex and age on electrocardiographic and cardiac electrophysiological properties in adults. Pacing Clin Electrophysiol 2001; 24: 16-21.

20. Mouzas IA, Pallis AG, Kochiadakisl GE, et al. Autonomic imbalance during the day in patients with inflammatory bowel disease in remission. Evidence from spectral analysis of heart rate variability over 24 hours. Digest Liver Dis 2002; 34: 775-780.

21. Nuti F, Viola F, Civitelli F, et al. Biological therapy in a pediatric crohn disease population at a referral center. JPGN 2014; 58: 582-587.

22. Yajnik V, Khan N, Dubinsky M, et al. Efficacy and safety of vedolizumab in ulcerative colitis and Crohn's disease patients stratified by age. Adv Ther 2017; 34: 542-559.

23. Coruzzi P, Castiglioni P, Parati G, Brambilla. Autonomic cardiovascular regulation in quiescent ulcerative colitis and Crohn's disease. Eur J Clin Invest 2007; 37: $964-$ 970.

24. Ganguli SC, Kamath MV, Redmond K, Chen Y. A comparison of autonomic function in patients with inflammatory bowel disease and in healthy controls. J Neurogastroenterol Motil 2007; 19: 961-967.

25. Engel T, Ben-Horin S, Beer-Gabel M. Autonomic dysfunction correlates with clinical and inflammatory activity in patients with Crohn's disease. Inflamm Bowel Dis 2015; 21: 2320-2326. 